\title{
OPINION
}

\section{Photographs and memories}

Notte Bianca and BOV Streets Alive were staged with the historic streets of Valletta as backdrop. During these recent events, I noted several persons, Maltese and tourists, taking photos. More than a photo, tourists will be taking home with them a memory - a memory of the city streets at their best. They will be taking with them stories they will tell their family and friends.

Surveys reveal that Valletta provides an exceptionally good experience for tourists during the daytime. With evening activities, Valletta can become an important tourism asset also in terms of evening leisure. Notte Bianca, BOV Streets Alive and similar events are an opportunity to provide a different and distinctly unique experience for the visitor.

BOV Streets Alive, organised by the Valletta Alive Foundation, consisted of a series of activities, in the streets of Valletta over four evenings in July and August. The tumout confirmed there is a demand for evening leisure and cultural activities in Valletta, something which was reconfirmed in a most emphatic nanner with the massive turnout at the Notte Bianca.

The foundation congratulates the Ministry for Tourism and Culture, the Malta Council for Culture and the Arts and all those who were involved. Congratulations also for the Malta Summer Arts Festival.

Apart from culture and leisure, these vents confirmed there is a potential for evening leisure shopping in Valletta, even if it may take longer for evening shopping in the city to become the norm. For BOV Streets Alive, several retailers reported significantly increased sales during July and August compared to the same time period last year.

These are opportunities which, it is hoped, the tourism industry will take note of. I remember some five or six years ago, tourism operators used to complain that there was not enough activities for tourists to engage in, especially in the evenings. This certainly is no longer the case. Numerous cultural and leisure activities take place throughout the year, mostly in our historic towns. With a little time and effort, tourism operators can obtain information about forthcoming cultural and leisure activities from the internet and from other sources.

1 know of one hotelier who actively encourages residents in his hotel to attend such activities

\section{Jobn Ebejer}

".. Valletta can become an important tourism asset also in terms of evening leisure."

and makes arrangements for their transport. By doing so he is making their stay in Malta more memorable, thereby increasing the chance of a repeat visit, probably to his same hotel. On the other hand, there may be some hoteliers who discourage tourists from engaging in activities outside the hotel, in an effort to increase spend ing within their premises. This is somewhat shortsighted because any entertainment provided within the hotel is likely to be similar to that of any other botel across the Mediterranean. It is our historic cities that provide the uniquely Maltese backdrop adding value to the visitor mperience and which, ultimately, is the most likely to result in a repeat visit and wordof-mouth promotion.

The foundation collaborated with the Malta Hotels and Restaurants Association in this year's BOV Streets Alive arid hopes to extend this collaboration in the coming year. The tar get will be to encourage raore tourists to participate in the event, an objective which; I am sure, organisers of the Notte. Bianca will also try to achieve.

Valletta will see several changes this coming year. The government has made it known that Merchants Street will be pedestrianised as part of the accessibility strategy for Valletta. $5 t$ John's Square will be upgraded and, hopefully, Castile Square will be redesigned and pedestrianised. These, combined with important events such as the Notte Bianca, the Malta Summer Arts Festival, the Historic Cities Festival and BOV Streets Alive will make the year 2007 a year to remember.

Mr Ebejer, an architect and urban planner, is honorary secretary of the Valletta Alve Foundation. 